\title{
Gestão do Conhecimento aplicado aos desastres naturais: o caso da Defesa Civil
}

\author{
Érico Soriano \\ Doutor; Universidade Federal de São Carlos, São Carlos, SP, Brasil; \\ ericogeo@gmail.com \\ Wanda Aparecida Machado Hoffmann \\ Doutora; Universidade Federal de São Carlos, São Carlos, SP, Brasil; \\ wanda@ufscar.br \\ Camila de Araujo \\ Doutora; Universidade Federal de Uberlândia, Uberlândia, MG, Brasil; \\ camiladearaujo@ufu.br
}

\begin{abstract}
Resumo: Os Órgãos de Proteção e Defesa Civil no Brasil possuem profissionais competentes para trabalhar na Gestão dos riscos de desastres naturais no país, uma vez que atuam diretamente nas áreas de risco e com os grupos populacionais vulneráveis a estes processos. Neste sentido, o conhecimento tácito e explícito desses profissionais é de grande importância para a prevenção e, principalmente, para as operações realizadas no enfrentamento do desastre e de outros momentos de crise. Porém, esse conhecimento é muitas vezes perdido em função da fragilidade institucional da Defesa Civil, especialmente em seu nível local. Desta forma, buscou-se fazer uma relação teórica sobre a aplicabilidade dos conceitos da Gestão do Conhecimento nos Órgãos de Defesa Civil, de forma a gerar conhecimentos para a melhoria no atendimento às ações de desastres naturais.
\end{abstract}

Palavras-chave: Gestão do conhecimento. Desastres naturais. Defesa Civil.

\section{Introdução}

Considerando-se a Gestão de Riscos de desastres naturais, em especial a etapa de prevenção, é de grande importância o conhecimento sobre Redução de Riscos de Desastres (RRD) dos profissionais da área, principalmente dos agentes de Defesa Civil que atuam diretamente no local e com os grupos populacionais vulneráveis a esses riscos, sendo que esses últimos precisam de um significativo conhecimento da verdadeira condição de risco dos municípios.

O objetivo deste estudo é realizar uma relação teórica sobre a aplicabilidade dos conceitos da Gestão do Conhecimento (GC) nos órgãos de 
Defesa Civil de forma a gerar conhecimentos para a melhoria no atendimento às ações de desastres naturais.

Para atender tal objetivo, foi realizada uma revisão da literatura sobre dois temas principais: (1) Atuação da Defesa Civil nos Desastres Naturais e (2) Gestão do Conhecimento. O segundo tema é um assunto extenso e bem consolidado na literatura acadêmica, assim, esta pesquisa realiza a revisão dos principais conceitos e autores da área, sem pretender esgotar o assunto, uma vez que o foco são as ferramentas da GC que podem contribuir para o trabalho da Defesa Civil.

Por fim, é realizado um levantamento das principais ferramentas da Gestão do Conhecimento que poderiam ser aplicadas para a Defesa Civil no intuito de otimizar as ações relacionadas aos desastres naturais.

\section{Os desastres naturais e a Defesa Civil}

Em busca de uma conceituação do termo desastre, a Secretaria Nacional de Defesa Civil o define como

\footnotetext{
Resultado de eventos adversos, naturais ou provocados pelo homem, sobre um ecossistema vulnerável, causando danos humanos, materiais e ambientais e consequentes prejuízos econômicos e sociais (BRASIL, 2007, p. 8).
}

Por desastres naturais, definem-se os fenômenos que ocorrem na biosfera e podem resultar em um evento prejudicial, causando a morte ou lesões, danos materiais, interrupção da atividade social e econômica e degradação ambiental (INTERNATIONAL STRATEGY FOR DISASTER REDUCTION, 2007).

O Atlas Brasileiro de Desastres Naturais indica que o registro de ocorrências de desastres naturais no país apontou um crescimento positivo de 268\% nos últimos dez anos (UNIVERSIDADE FEDERAL DE SANTA CATARINA, 2012). De acordo com Valencio (2014), os desastres são um problema crônico no Brasil, aos quais as políticas adotadas no âmbito do Sistema Nacional de Proteção e Defesa Civil (SINPDEC) não têm conseguido resolver. 
Situações de desastre são caracterizadas pela dificuldade na previsão, pelos enormes danos à sociedade, e pelo curto tempo de decisão (ZHANG; ZHOU; NUNAMAKER JR., 2002). A ocorrência e a recorrência de desastres de diversas naturezas exigem um nível de organização e preparo para a redução da vulnerabilidade e do número de vítimas fatais. Segundo Braga et al. (2011), para o enfrentamento dos desastres naturais, faz-se necessária uma melhor atividade de gestão de desastres no país, através do envolvimento de todos os atores Governo, Defesa Civil e as comunidades atingidas, assim como a utilização de diversas ferramentas tecnológicas apropriadas para este processo.

A Defesa Civil é o órgão público cuja missão é promover, coordenar e supervisionar as ações de resultados desastrosos ou prejudiciais, ao Estado ou à sua população, e de assistência e atendimento às necessidades da população, decorrentes de situações de emergência ou de estados de calamidade pública (CASTRO, 1998), ou seja, o órgão competente para o desenvolvimento da prevenção dos riscos, que podem se configurar em desastres, e no enfrentamento logo após o desastre, na busca pela redução da vulnerabilidade e das consequências do evento.

O Decreto $\mathrm{n}^{\circ}$ 97.274, de 16 de dezembro de 1988, da Constituição Federal instituiu o Sistema Nacional de Defesa Civil no país. De acordo com o Artigo $1^{\circ}$, parágrafo único, a defesa civil é “[...] o conjunto de medidas destinadas a prevenir, limitar ou corrigir os riscos e danos pessoais ou materiais decorrentes de estado de calamidade pública ou de situação de emergência [...]". (BRASIL, 1988).

O Sistema Nacional de Defesa Civil (SINDEC) está constituído, desde 1995, com a instituição da Política Nacional de Defesa Civil. Compõem-se de órgãos e entidades da Administração Pública Federal, dos estados, do Distrito Federal, da Defesa Civil e do Ministério da Integração Regional. Os objetivos são: planejar e promover a defesa permanente contra os desastres de origem natural ou antrópicos, de maior prevalência no país; realizar estudos, avaliar e reduzir riscos de desastres; prevenir ou minimizar danos, socorrer e assistir as populações afetadas e reabilitar e reconstruir os cenários deteriorados pelos 
desastres; atuar na iminência e em circunstâncias de desastres; promover a articulação e coordenar os órgãos do SINDEC em todo o território nacional.

Embora se configure no principal órgão público de proteção civil para mitigar as consequências de um desastre, a Defesa Civil apresenta uma série de dificuldades estruturais e de recursos que limitam suas ações. Segundo Valencio (2008, doc. sem paginação):

A atuação do Estado em relação ao risco no Brasil é, no mínimo, preocupante. Demandaria muitas considerações, mas o que posso afirmar como o ponto central é que, de um lado, temos uma Secretaria Nacional que precisa dar conta de coordenar esforços intersetoriais em todas as fases (da prevenção à recuperação) do desastre; mas ela própria se revela como um setor, submetida a um jogo político-partidário que suplanta a qualidade técnica das ações que os seus quadros precisam e devem fazer. [...] A atual ineficácia das ações de prevenção e preparação resultou no dispêndio de um bilhão de reais para refazer obras em vários estados da federação, quando poderia ser um montante destinado a novos investimentos, isso, num contexto de crise financeira global. De outro, melhor articulando as demais secretarias de Estado e ministérios nas ações intersetoriais para reduzir a vulnerabilidade.

O SINDEC (BRASIL, 2007) afirma que os principais problemas relacionados ao atendimento às emergências e desastres não se restringem a falta de recursos financeiros. Considera que os principais problemas que impedem ou dificultam o atendimento aos desastres no Brasil são:

a) o "fenômeno da indiferença - a inércia" - da população e das autoridades de governo para a gravidade e importância dos desastres. Portanto, é a falta de decisão política;

b) a ausência de conscientização e participação da população, inclusive nas decisões importantes, planejamento de estratégias, ações, etc. Deve haver participação plena, consciente e eficiente. Os países com uma Defesa Civil muito eficiente contam com ampla e plena participação da população;

c) outro problema que ainda persiste no Brasil, em todos os níveis da sociedade, é a ideia de que o controle de desastre deva ser apenas na iminência de o mesmo ocorrer ou depois que acontece. (BRASIL, 2007, p.12).

Desta forma, o SINDEC busca culpabilizar a sociedade por apresentar uma inércia em relação aos desastres. Ou seja, a responsabilidade deveria ser da sociedade pela sua alienação em relação às atividades da Defesa Civil. Alienação que se relaciona com o processo de vulnerabilização da sociedade, 
uma vez que lhe é negado o conhecimento e as práticas das arenas participativas e de tomada de decisão. Neste sentido, quem deveria buscar uma alternativa de mobilizar grupos sociais para as discussões sobre riscos e desastres deve ser a própria Defesa Civil, que deve desenvolver uma prática dialógica entre o conhecimento técnico e o conhecimento das pessoas (SORIANO, 2012). Vale lembrar que a conscientização pública é um fator chave na redução eficaz do risco de desastres (INTERNATIONAL STRATEGY FOR DISASTER REDUCTION, 2007).

Porém, mesmo face a tal necessidade, destacam-se as dificuldades e o caráter precário de muitos órgãos municipais de defesa civil no país, dados dois pontos principais: a formação e conhecimento técnico dos agentes que compõe a Defesa Civil e a estrutura institucional da Defesa Civil.

Sobre o primeiro ponto, de acordo com Braun (2006 ${ }^{1}$ apud LONDE; SORIANO; COUTINHO, 2015, p. 79):

A estruturação efetiva da Defesa Civil deve ser permeada por conhecimento técnico, com profissionais capacitados e instruídos para trabalhar na prevenção de desastres e prontos para enfrentá-los, o que consiste em medidas de curta e longa duração, planejadas para salvar vidas e limitar os danos que possam ser causados.

De acordo com a Lei $\mathrm{n}^{\mathrm{o}}$ 12.608, de 10 de abril de 2012, que Institui a Política Nacional de Proteção e Defesa Civil - PNPDEC; dispõe sobre o Sistema Nacional de Proteção e Defesa Civil - SINPDEC e o Conselho Nacional de Proteção e Defesa Civil - CONPDEC, no Art. 18, para fins do disposto nesta Lei, consideram-se agentes de proteção e defesa civil:

I - os agentes políticos da União, dos Estados, do Distrito Federal e dos Municípios responsáveis pela direção superior dos órgãos do SINPDEC;

II - os agentes públicos responsáveis pela coordenação e direção de órgãos ou entidades públicas prestadores dos serviços de proteção e defesa civil;

III - os agentes públicos detentores de cargo, emprego ou função pública, civis ou militares, com atribuições relativas à prestação ou execução dos serviços de proteção e defesa civil; e

IV - os agentes voluntários, vinculados a entidades privadas ou prestadores de serviços voluntários que exercem, em caráter suplementar, serviços relacionados à proteção e defesa civil (BRASIL, 2012). 


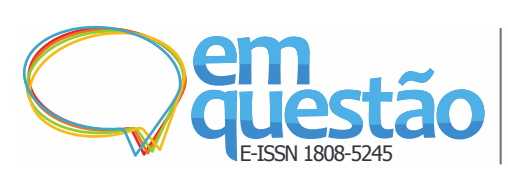

Ainda de acordo com o Art. 18, Parágrafo único:
Gestão do Conhecimento aplicado aos desastres naturais: o caso da Defesa Civil

Érico Soriano, Wanda Machado Aparecida Hoffmann, Camila de Araujo

Os órgãos do SINPDEC adotarão, no âmbito de suas competências, as medidas pertinentes para assegurar a profissionalização e a qualificação, em caráter permanente, dos agentes públicos referidos no inciso III (BRASIL, 2012).

Desta forma, é possível observar que não existe uma diretiva que regularize e padronize a adoção de medidas que assegurem a profissionalização dos agentes de Defesa Civil, em todo o território nacional. Assim, destaca-se a baixa formação dos agentes em muitos casos. De acordo com Queiroz $\left(2010^{2}\right.$ apud QUEIROZ; BODSTEIN, 2011, p. 17-18),

\begin{abstract}
A atual Política Nacional de Defesa Civil (PNDC), não obstante os avanços por ela consignados, não logrou instrumentalizar uma visão integrada do objeto e das práticas da Defesa Civil, criando uma estrutura piramidal cuja base é extremamente frágil. Em todos os níveis de atuação e principalmente na base desta pirâmide, há necessidade de um maior nível de capacitação técnico-profissional dos atores bem envolvidos, o que não poderá ser feito sem a criação de uma carreira estruturada e bem definida em seus objetivos políticos e sociais. A criação de uma carreira em Defesa Civil asseguraria a continuidade dos esforços, minimizando e, eventualmente, erradicando o impacto dos interesses políticos passageiros, que não se pretendem maiores do que a duração de um mandato eleitoral.
\end{abstract}

Sobre o segundo ponto - estrutura institucional da Defesa Civil, a fragilidade da defesa civil corresponde aos níveis de governo e aos entraves burocrático-partidários que dificultam a representação homogênea do órgão em todas as regiões. O problema se dá no fato de que a Secretaria Nacional de Defesa Civil é um órgão federal. As esferas estaduais de defesa civil respondem à Secretaria Nacional de Proteção e Defesa Civil (SEDEC). Porém, em muitos casos, os membros das Secretarias Estaduais são bombeiros, ou seja, soldados militares com uma função de proteção civil, mas que estão subordinados ao governador dos seus estados e seus respectivos mandatos. O mesmo se observa em relação às esferas municipais de defesa civil, onde os agentes ou são bombeiros e respondem ao governador e à SEDEC, ou são guardas municipais respondendo ao prefeito municipal e também ao seu tempo de mandato. Essas situações se complicam quando se observa alguma disputa partidária entre as 
esferas de governo, assim também como não se observa uma homogeneidade de formações e interesses nos diferentes níveis de defesa civil (SORIANO, 2012).

Os órgãos locais de Defesa Civil representam a ponta de todo um Sistema Nacional de Proteção e Defesa Civil, ou seja, são os responsáveis pelas ações de prevenção nos grupos populacionais vulneráveis. Desta forma, conhecem os pontos críticos, as áreas de risco e a vulnerabilidade da população na prática. A mudança no quadro de funcionários e de comando destes órgãos pode representar uma perda de conhecimento muito grande para a prevenção de desastres naturais. Então, o plano de carreira de Defesa Civil pode representar um maior conhecimento institucional e dos agentes em relação às áreas de risco e à população vulnerável a estes riscos (LONDE; SORIANO; COUTINHO, 2015). Desta forma, não apenas a formação dos agentes é importante, mas também a continuidade das atividades, independentemente da mudança de prefeitos e governadores, dada a importância do conhecimento tácito e explícito dos agentes de Defesa Civil, sendo esse conhecimento um instrumento de grande importância para as atividades de proteção civil e de prevenção de riscos de desastres, bem como o fortalecimento da geração de novos conhecimentos.

Segundo Ventura e Nassif (2016, p. 31):

Faz-se mister que a organização compreenda que não só a cultura informacional precisa ser estimulada, mas também todo o contexto formal necessita ser repensado, procurando implantar uma estrutura organizacional que favoreça o trabalho em equipe e diminua o nível de política.

Tem-se, então, a sinergia dos pontos citados e a necessidade de uma gestão mais eficiente sobre este conhecimento adquirido e que muitas vezes é perdido.

\section{A Gestão do Conhecimento}

Em uma organização pode existir uma grande quantidade de dados que geram informações e que, posteriormente, podem gerar conhecimento. Entende-se o conceito de informação como "[...] dados coletados, organizados, orientado aos quais são atribuídos significados e contexto.” (MCGEE; PRUSAK, 1994, p. 23). Já o conhecimento é uma "[...] mistura fluida de experiência condensada, 
valores, informação contextual e insight experimentado, a qual proporciona uma estrutura para avaliação e incorporação de novas experiências e informações”. (DAVENPORT; PRUSAK, 1998, p. 6). Assim, o conhecimento de uma organização é o resultado de seus anos de atividade organizacional na qual o conhecimento individual é combinado, gerando o todo coletivo (KOGUT; ZANDER, 1992).

A partir do final dos anos 1980, em meio ao ambiente competitivo e de rápidas mudanças, caracterizado pela sobrecarga de informações que tomou conta das organizações, surge a Gestão do Conhecimento (BARCELOVALENZUELA et al., 2008).

Antes de apresentar o conceito de Gestão do Conhecimento, é importante deixar claro que o conhecimento dos indivíduos que participam das organizações é composto tanto de conhecimento tácito como de conhecimento explícito. Nonaka e Takeuchi (1997) afirmam que o conhecimento tácito é altamente pessoal, específico a algum contexto e difícil de formalizar. Os mesmos autores apresentam que o conhecimento explícito pode ser expresso em palavras e números, em linguagem formal e facilmente comunicado.

Assim, as organizações necessitam de técnicas de gestão e procedimentos sistemáticos que visam identificar e utilizar, de forma otimizada, as informações e o conhecimento, tanto tácito como explícito, gerado em todas as etapas do processo produtivo, buscando atingir um melhor desempenho organizacional e financeiro de uma determinada organização pública ou privada. Esse processo de gestão é denominado por Gestão do Conhecimento (GAMBLE; BLACKWELL, 2001; TATHAM; SPENS, 2011).

O maior alvo de estudos e aplicações da Gestão do Conhecimento se encontra no ambiente empresarial. Porém, é um campo de estudo amplo, utilizado por outras áreas, tais como: Sistemas de Informação, estudos de Gestão, Sociologia, Ciência da Informação, Engenharia de Produção, Psicologia, dentre outros (VON KROGH, 2002).

Para Sveiby (1998), a Gestão do Conhecimento consiste na geração de valor através da utilização dos bens intangíveis de uma organização. Na mesma linha, Silveira (2004, p.40) afirma que a 
Gestão do Conhecimento é, antes de tudo, uma nova forma de se trabalhar, uma nova cultura organizacional, na qual o ambiente e os valores permitam gerar a motivação necessária à aprendizagem, ao compartilhamento ou mesmo à transferência e à aplicação do conhecimento.

De acordo com Murray (1996), a Gestão do Conhecimento é uma estratégia que transforma bens intelectuais da organização - informações registradas e o talento dos seus membros - em maior produtividade, novos valores e aumento de competitividade. Representa um processo sistemático de fluxo de informações, conhecimento e geração de novos conhecimentos resultando no aumento da eficiência e da inovação (CASTILLO; CAZARINI, 2009), alcançadas:

[...] através da criação, compartilhamento e aplicação do conhecimento, bem como através da alimentação as valiosas lições aprendidas e melhores práticas para a memória corporativa, a fim para promover a aprendizagem organizacional continuada (DALKIR, 2005, p. 3).

Hoffmann (2016, p. 9) afirma que a Gestão do Conhecimento:

Possui como propósito gerenciar o conhecimento das pessoas e organizações, através do acesso, coleta, tratamento e análise das informações e seu compartilhamento em ambientes ou espaços físicos ou virtuais que oferecem um contexto apropriado para a geração e uso do conhecimento, onde as pessoas se reúnem, fazem reflexões críticas, compartilham experiências e melhores práticas, em que efetivamente se comunicam, possibilitando a interação entre o conhecimento tácito e o conhecimento explícito.

Observa-se, então, que a informação e o conhecimento possuem um papel fundamental em um ambiente organizacional como elementos indispensáveis para a tomada de decisões (VALENTIM, 2007), para que se possa compreender e responder às mudanças ambientais e manter a organização em uma posição favorável no mercado (BEAL, 2012). Portanto, as organizações utilizam a Gestão do Conhecimento como um modelo de gestão que visa melhorar o desempenho, evitando-se a perda e/ou a má utilização do conhecimento criado, disseminado e compartilhado.

Desta forma, a Gestão do Conhecimento é mais que a agregação de projetos, metodologias e ferramentas: significa compromisso com a 
transparência; foco nos processos em vez da hierarquia, com uma visão integradora; uso e reuso eficaz de informações e conhecimentos, boas práticas de gestão e expertises; uso eficaz de novas Tecnologias de Informação e Comunicação; e, no contexto do setor público, principalmente, foco em atender as necessidades dos cidadãos.

As ações listadas, portanto, têm um objetivo amplo de modernização dos processos de gestão do setor público de acordo com as mais modernas técnicas de gestão adotadas por organizações de ponta dos setores privados e públicos, tanto no Brasil como nos países desenvolvidos (BATISTA et al., 2005).

Um dos principais desafios de gestão de uma organização pública, principalmente considerando a questão da eficiência, é a de superar uma cultura organizacional, que pode dificultar o seu desenvolvimento. Para Patias e Minho (2012), o fator cultural em uma empresa é um fator responsável para que determinada organização seja resistente ao novo e faz com que as tarefas sejam realizadas sempre da mesma maneira. Desta forma, a cultura organizacional não permite a implementação de melhorias, provocando insatisfação e desmotivação nos funcionários, uma vez que é inflexível a mudanças.

De acordo com Pires e Macêdo (2006, p.100), as empresas públicas apresentam algumas características em comum que caracterizam sua cultura organizacional, destacando-se, para este trabalho, a "[...] descontinuidade da gestão, que leva ao reformismo projetos de curto prazo com conflitos de objetivos e gestão nem sempre profissionalizada."

A cultura de organizações públicas leva essas mesmas organizações a burocracias públicas tradicionais que além de terem se tornado complexas, com características centralizadoras e estruturas rígidas, não têm sido orientadas para o atendimento das necessidades dos cidadãos, ou para a eficácia e efetividade. Para tanto, difundem-se no setor público inovações consideradas exitosas no setor empresarial, sem que se considerem objetivos e valores predominantes na administração pública. (PIRES; MACEDO p. 100).

A ausência de uma cultura organizacional voltada a uma maior integração entre as pessoas, promovendo encontros e socialização dos conhecimentos, há uma grande probabilidade de que os empregados guardem os 
conhecimentos produzidos para si, além de dificultar o processo de Gestão de Conhecimento em uma empresa (INAZAWA, 2009).

Desta forma, ressalta-se a importância da consideração da cultura organizacional durante a implementação da Gestão do Conhecimento. Porém, de acordo com Inazawa (2009, p. 211), “[...] este processo poderá vir a se tornar bastante difícil se a cultura organizacional não privilegiar o desenvolvimento de uma cultura voltada à aprendizagem e ao compartilhamento do conhecimento.”. Segundo Hoffmann (2009), a cultura organizacional é uma das principais barreiras para GC. Alinha-se também a questão dos aspectos estruturais das organizações (SILVA, 2011).

Neste sentido, Batista (2004, p. 9) afirma que organizações públicas devem gerir o conhecimento com o objetivo de:

i) Tratar de maneira adequada e com rapidez desafios inesperados e desastres;

ii) Preparar cidadãos, organizações não-governamentais e outros atores sociais para atuar como parceiros do Estado na elaboração e na implementação de políticas públicas;

iii) Promover a inserção social, a redução das desigualdades sociais e um nível aceitável de qualidade de vida para a população por meio de construção, manutenção e ampliação do capital social e do capital intelectual das empresas;

iv) Criar uma sociedade competitiva na economia regional e global por meio da educação dos cidadãos para que eles se tornem trabalhadores competentes do conhecimento, e mediante o desenvolvimento das organizações para que estas se tornem competitivas em todas as áreas do conhecimento.

Uma vez que os desastres se caracterizam pela dificuldade de previsão, elevados danos à sociedade e pouco tempo de decisão, o conhecimento nas ações preventivas e mitigadoras oferece às pessoas condições de tomada de decisões e resposta adequada ao problema em tempo hábil. Neste caso, uma Gestão do Conhecimento fortalecida pelo uso de suas ferramentas auxilia a aquisição e a disseminação das informações mais adequadas ao processo. Pode, também, ajudar os tomadores de decisão a realizarem seu trabalho mais rápido e de forma mais eficiente, além de permitir que vários grupos compartilhem e reutilizem recursos (ZHANG; ZHOU; NUNAMAKER JR., 2002). Reforça-se, então, a importância da geração do conhecimento no cenário de desastres 
naturais, sendo que o empenho institucional se concentra na resposta ao desastre, ou em investimentos na prevenção. Paulucci (2013) destaca que embora a importância do conhecimento criado no cenário pertinente seja notória, as ações se concentram na prevenção dos desastres e nas ações de resposta. A autora afirma também que

[...] pouco se tem falado sobre as informações que geram conhecimento que pode ser utilizado na preparação para os desastres naturais que contribuiria com um melhor enfrentamento e por consequência um atendimento melhor a população afetada (PAULUCCI, 2013, p. 73).

Desta forma, para a Defesa Civil realizar a gestão do conhecimento com os objetivos apresentados, as ferramentas da GC são discutidas a seguir.

\section{Ferramentas e melhores práticas de GC para a Defesa Civil}

Este estudo considera os órgãos locais de Proteção e Defesa Civil como uma organização pública. Este modelo de administração, como é o caso das Defesas Civis, caracteriza-se pela perda de uma parte expressiva do conhecimento e das informações acumuladas através das mudanças de gestão e da falta de uma memória organizacional. Esta situação pode representar um retrocesso no processo de geração do conhecimento, assim como a consequente perda da eficiência nas atividades desenvolvidas.

Para Wiig (2000), a Gestão do Conhecimento pode contribuir para a melhoria da administração pública, aumentando a efetividade dos serviços públicos, permitindo um melhor atendimento público. De acordo com Schlesinger et al. (2008, p. 39), as organizações públicas têm a obrigação de aumentar sua eficiência, e gerir novos conhecimentos para:

Encontrar a maneira mais adequada para responder aos desafios; possibilitar que atores sociais (cidadãos, organizações nãogovernamentais e outros) atuem como parceiros do Estado na elaboração e implementação de políticas públicas; contribuir para que a população seja inserida socialmente, reduzindo as desigualdades e melhorando a qualidade de vida por meio de construção, manutenção e ampliação do capital social e do capital intelectual das organizações; possibilitar a educação dos cidadãos para que eles se tornem trabalhadores competentes do conhecimento, mediante o desenvolvimento das organizações em todas as áreas do conhecimento. 
A Defesa Civil representa um caso interessante para um estudo relacionado à Gestão do Conhecimento por dois motivos: o primeiro por apresentar as características e as dificuldades de uma administração pública, tais como: constantes mudanças de comando e do corpo de funcionários em diferentes gestões e mandatos; assim como pela importância da velocidade e da eficiência no seu trabalho, que pode salvar vidas. Neste sentido, destaca-se a importância e o desafio de se criar uma cultura organizacional de Gestão do Conhecimento em órgãos dessa natureza.

As ferramentas utilizadas na Gestão do Conhecimento representam o conjunto de metodologias, técnicas e tecnologias de informação com a finalidade de apoiar o desenvolvimento e avaliar as práticas de determinada organização (CASTILLO; CAZARINI, 2009). Dentre as ferramentas utilizadas pela Gestão do Conhecimento, foram elencadas algumas (BRAGA et al., 2011; RAO, 2005; ROBERTSON; BRUN; SERVIN, 2005) que podem ser aplicadas na questão informacional e no gerenciamento do risco de desastres naturais com a possibilidade de serem utilizados pelos órgãos de proteção e defesa civil, a saber:

a) revisão de ações realizadas - objetiva capturar as lições aprendidas durante e após algumas atividades ou projetos realizados. Esta ferramenta é fundamental para as atividades de defesa civil, buscando registrar o conhecimento criado em determinada atividade, buscando corrigir os erros e acumulando experiência sobre determinada situação, além de transmitir o conhecimento para os agentes que não participaram da ocorrência;

b) entrevistas de desligamento - série de procedimentos, como questionários e entrevistas, utilizados para a obtenção de informações do funcionário que está deixando alguma empresa, principalmente relacionadas a processos de comunicação, gestão, opiniões, etc. Desta forma, uma parte do conhecimento adquirido pelo funcionário não se perde através da mudança do quadro de servidores. Uma ferramenta fundamental para os órgãos de defesa civil, uma vez que os agentes acumulam um elevado conhecimento tácito e explícito dos municípios 
em que trabalham, identificando áreas de risco, diferentes níveis de vulnerabilidade dos grupos populacionais, diferentes limiares para deslizamento, etc.;

c) comunidades de prática - são grupos de pessoas que compartilham a prática de seus conhecimentos em uma área do saber, através da reunião de grandes especialistas na área para o intercâmbio de informações. Ainda não há no país um ambiente virtual de troca de informações e conhecimento sobre riscos de desastres, aberto para o público interessado. O que existe é o Sistema Integrado de Informações sobre Desastres (S2ID), que visa informatizar o processo de transferência de recursos em virtude de desastres. O objetivo é qualificar e dar transparência à gestão de riscos e desastres no Brasil, já que, além de agilizar o processo, garante o acesso às informações sobre desastres em diversos níveis (BRASIL, 2012). Porém, se restringe a profissionais de Defesa e Proteção Civil;

d) gestão de conteúdo - vão desde a elaboração de wikis e blogs, passando pela construção de conteúdos para aprendizagem futura até o gerenciamento eletrônico de documentos. Esta ferramenta pode ser interessante para a Defesa Civil, considerando-se o alcance e a agilidade do fluxo de informações da internet, principalmente com o intermédio em tempo real dos smartphones. Neste sentido, podem ser desenvolvidas plataformas de comunicação simples e objetivas com a população;

e) auditorias de conhecimento - processo sistemático para agregar valor nas organizações por meio da Gestão do Conhecimento, identificando suas necessidades, fluxos e ativos de conhecimento;

f) melhores práticas - buscam identificar, capturar e compartilhar as melhores práticas nas diversas atividades organizacionais;

g) análise de redes sociais - visa mapear as relações entre os especialistas, grupos ou organizações, identificando o fluxo deste conhecimento específico e os atores chave, para compreender como essas relações favorecem ou dificultam o fluxo do conhecimento; 
h) páginas amarelas - objetiva a criação de um banco de competências na organização para facilitar a localização de pessoas com conhecimentos específicos;

i) aprendizagem virtual - através do processo de treinamento, qualificação e formação dos diversos integrantes de determinada organização através de tecnologias que permitam a educação a distância, em ambiente virtual. Considerando-se o caso das Defesas Civis, se apresenta interessante porque permite a ampliação do número de profissionais qualificados e, ao mesmo tempo, não há a necessidade de se ausentarem do ambiente de trabalho para esta qualificação, estando disponíveis para alguma ocorrência.

De acordo com Braga et al. (2011), as ferramentas de Gestão do Conhecimento apresentam bons resultados em diversas áreas e situações. Desta forma, pela teoria apresentada, é possível afirmar a sua contribuição nas melhorias das etapas de Gestão dos Riscos, portanto, fundamentais para os órgãos de proteção e Defesa Civil no país, em todos os níveis.

\section{Considerações finais}

A Gestão do Conhecimento envolve uma série de procedimentos que visam diferentes objetivos, dependendo do escopo e dos objetivos de determinada organização ou instituição. O ponto em comum nestes procedimentos, que é a adoção de técnicas e ferramentas específicas, é gerar, preservar, disseminar e não perder o conhecimento gerado por diferentes processos individuais e coletivos.

Este conhecimento, também chamado de capital intelectual, é gerado através da capacitação, processos de produção, desenvolvimento, integração e de comunicação, é o que permite a adoção de melhorias contínuas, assim como pode proporcionar mais eficiência para a instituição.

Neste sentido, espera-se que uma Defesa Civil com funcionários capacitados e com plano de carreira adequado seja uma alternativa capaz de mudar a situação atual, onde prevalecem a descontinuidade nas ações 
programadas e a falta de planejamento nas ações preventivas. A continuidade e sistematização das atividades garantem um maior conhecimento dos agentes em relação às áreas de risco e à população vulnerável, além da melhoria do processo de comunicação e do aumento da confiança da população em relação aos agentes já conhecidos.

Portanto, no que diz respeito ao objetivo principal deste trabalho, a adoção de ferramentas da Gestão do Conhecimento nas atividades relacionadas à Gestão de Riscos pode reduzir a fragilidade institucional e operacional da Defesa Civil, favorecendo o ganho de eficiência e o cumprimento efetivo dos seus objetivos, o que pode representar a redução da vulnerabilidade de determinados grupos populacionais, assim como do número de vítimas fatais.

Porém, apesar de tal constatação, este trabalho limita-se a analisar a possibilidade de aplicação da GC para os desastres naturais sem considerar questões políticas e de poder no compartilhamento da informação. Acredita-se que outros estudos poderiam ser desenvolvidos considerando tais questões e as barreiras que elas geram diretamente no objeto deste estudo.

\section{Financiamento}

Agradecimento a Fundação de Amparo a Pesquisa do Estado de São Paulo (FAPESP) processo no 2014/06253-0.

\section{Referências}

BATISTA, F. F. Governo que aprende: gestão do conhecimento em organizações do Executivo Federal. Brasília, DF: IPEA, 2004. Disponível em: <http://www.ipea.gov.br>. Acesso em: 15 jun. 2013. (Texto para discussão, n. 1022).

BATISTA, F. F. et. al. Gestão do conhecimento na administração pública. Brasília, DF: IPEA, 2005. (Texto para discussão, n. 1095).

BARCELO-VALENZUELA, M. et al. Defining the problem: key element for the success of knowledge management. Knowledge Management Research \& Practice, Basingstoke, v. 6, n. 4, p. 322-333, 2008.

BEAL, A. Gestão estratégica da informação. São Paulo: Atlas, 2012. 
BRAGA, M. M. et al. Aplicação das técnicas de gestão do conhecimento no gerenciamento de desastres naturais. In: SIMPOSIO SOCIEDAD DE LA INFORMACIÓN, 2011, Cordoba. Anales de las 40 Jornadas Argentinas de Informática. Buenos Aires: SADIO, 2011. p. 111-125.

BRASIL. Constituição (1988). Constituição da Republica Federativa do Brasil. Brasília, DF: Senado Federal Centro Gráfico, 1988. 292 p.

BRASIL. Lei n ${ }^{\circ} 12.608$, de 10 de abril de 2012. Institui a Política Nacional de Proteção e Defesa Civil - PNPDEC... Diário Oficial da União, Brasília, DF, 12 abr. 2012. Disponível em: <http://www.planalto.gov.br/ccivil_03/_Ato20112014/2012/Lei/L12608.htm>. Acesso em: 18 jul. 2014.

BRASIL. Ministério da Integração Nacional. Secretaria Nacional da Defesa Civil. Sistema Integrado de Informações sobre Desastres (S2ID). [2012]. Disponível em: <http://www.integracao.gov.br/defesacivil〉. Acesso em: 25 out. 2012.

BRASIL. Conferência geral sobre desastres: para prefeitos, dirigentes de instituições públicas e privadas e líderes comunitários. Brasília: Secretaria Nacional da Defesa Civil, 2007.

BRASIL. Ministério de Integração Nacional. Secretaria Nacional de Defesa Civil. Política Nacional de Defesa Civil. Brasília, 2007. Disponível em: <http://www.defesacivil.gov.br.>. Acesso em: 30 set. 2009.

CASTILLO, L. A. M.; CAZARINI, E. W. Modelo integrado para a implantação da gestão do conhecimento. In: SIMPÓSIO DE ENGENHARIA DE PRODUÇÃO, 16., 2009, Bauru. Anais... Bauru: UNESP, 2009.

CASTRO, L. A. Glossário de Defesa Civil: estudos de riscos e medicina de desastres. 2.ed. Brasília: Ministério do Planejamento e Orçamento/Departamento de Defesa Civil, 1998.

DALKIR, K. Knowledge management in theory and practice. Burlington: Elsevier Butterworth-Heinemann, 2005.

DAVENPORT, T. H.; PRUSAK, L. Conhecimento empresarial. Rio de Janeiro: Campus, 1998.

GAMBLE, P. R.; BLACKWELL, J. Knowledge management. London: Kegan Paul, 2001.

HOFFMANN, W. A. M. (Org.). Construções interdisciplinares em gestão do conhecimento. São Carlos: Pedro \& João Editores, 2016.

HOFFMANN, W. A. M. Gestão do conhecimento: desafios de aprender. São Carlos: Compacta, 2009. 
INAZAWA, F. K. O papel da cultura organizacional e da aprendizagem para o sucesso da gestão do conhecimento. Perspectivas em Ciência da Informação, Belo Horizonte, v. 14, n. 3, p. 206-220, set./dez. 2009.

INTERNATIONAL STRATEGY FOR DISASTER REDUCTION. Lessons for a safer future: drawing on the experience of the Indian Ocean tsunami disaster: eleven keys actions for building nations' and communities' resilience to disasters. Geneva, 2007.

KOGUT, B.; ZANDER, U. Knowledge of the firm, combinative capabilities, and the replication of technology. Organization Science, Providence, v. 3, n. 3, p. 383-97, 1992.

LONDE, L. R.; SORIANO,E.; COUTINHO, M. P. Capacidades das instituições municipais de proteção e defesa civil no Brasil: desafios e perspectivas. Revista do Departamento de Geografia, São Paulo, v. 30, p. 77-95, dez. 2015.

MCGEE, J. V.; PRUSAK, L. Gerenciamento estratégico da informação. Rio de Janeiro: Elsevier, 1994.

MURRAY, P. C. New language for new leverage: the terminology of knowledge management (KM). 1996. Disponível em:

<http://www.ktic.com/topic6/13_TERM0.HTM>. Acesso em: 10 ago. 2015.

NONAKA, I.; TAKEUCHI, H. Criação de conhecimento na empresa: como as empresas japonesas geram a dinamica da inovação. São Paulo: Campus, 1997.

PATIAS, T. Z.; MINHO, C. S. V. As influências da cultura organizacional na prestação de serviços públicos. 2012. Disponivel em:

<http://www.escoladegoverno.rn.gov.br/contentproducao/aplicacao/searh_eg/im prensa/pdf/035.pdf>. Acesso em: 18 mar. 2015.

PAULUCCI, M. R. B. C. O Fluxo informacional para as ações de resposta a desastres naturais em áreas urbanas com base na logística humanitária. 2013. 163 f. Dissertação (Mestrado em Ciência, Tecnologia e Sociedade) Programa de Pós-Graduação em Ciência, Tecnologia e Sociedade, Centro de Estudos em Ciências Humanas, Universidade Federal de São Carlos, São Carlos, 2013.

PIRES, J. C. S.; MACÊDO, K. B. Cultura organizacional em organizações públicas no Brasil. Revista de Administração Pública, Rio de Janeiro, v. 1, n. 40, p. 81-105, jan./fev. 2006.

QUEIROZ, E.; BODSTEIN, A. Território e bacias hidrográficas: reflexões a propósito da gestão de recursos hídricos e seus possíveis desdobramentos sobre 
as práticas de Defesa Civil frente aos desastres de origem hídrica. Revista Científica Internacional, Campos dos Goytacazes, v. 1, n. 16, jan./mar. 2011.

RAO, M. Knowledge management tools and techniques: practitioners and experts evaluate knowledge management solutions. Oxford: Elsevier Butterworth-Heinemman. 2005.

ROBERTSON, S.; BRUN, C.; SERVIN, G. ABC of knowledge management. [S.1.]: National Library for Health, 2005. Disponível em:

<http://www.library.nhs.uk/SpecialistLibrarySearch/download.aspx?resID=1264 03>. Acesso em: 30 set. 2012.

SCHLESINGER, C. C. B. et al. Gestão do conhecimento na administração pública. Curitiba: Imap, 2008.

SILVA, R. S. G. Proposta de diretrizes para o desenvolvimento da gestão do conhecimento por meio de comunidades de prática. 2011. 103 f. Dissertação (Mestrado) - Programa de Pós-Graduação em Engenharia de Produção, Escola de Engenharia de São Carlos, Universidade de São Paulo, São Carlos, 2011.

SILVEIRA, A. A. Gestão do conhecimento como ênfase na aprendizagem organizacional: um estudo de multicaso no contexto bancário. 2004. Dissertação (Mestrado em Engenharia de Produção)-Programa de PósGraduação em Engenharia de Produção, Universidade Federal de Itajubá, Itajubá, 2004.

SORIANO, E. Confiança, incertezas e discursos sobre os riscos de colapso de barragem na UHE Itaipu Binacional: o processo de vulnerabilização dos moradores a jusante. 2012. 184 f. Tese (Doutorado em Ciências da Engenharia Ambiental) - Programa de Pós-Graduação em Ciências da Engenharia Ambiental, Universidade de São Paulo, São Carlos, 2012.

SVEIBY, K. E. A nova riqueza das organizações: gerenciando e avaliando patrimônios de conhecimento. Rio de Janeiro: Campus, 1998.

TATHAM, P.; SPENS, K. Towards a humanitarian logistics knowledge management system. Disaster Prevention and Management, [S.1.], v. 20, n. 1, p. 6-26, 2011.

UNIVERSIDADE FEDERAL DE SANTA CATARINA. Centro Universitário de Estudos e Pesquisas sobre Desastres. Atlas brasileiro de desastres naturais 1991 a 2010: volume Brasil. Florianópolis, 2012.

VALENCIO, N. F. L.S. Entrevistas [2008]. ComCiência: Revista Eletronica de Jornalismo Científico, Campinas, 10 dez. 2008. Entrevista concedida a Alessandro Piolli. 
SILVA, A. A. Mulheres no ataque: depoimento. [9 de junho, 1996]. São Paulo: Revista da Folha de São Paulo. Entrevista concedida a Cristiana Couto.

VALENCIO, N. F. L. S. Disasters: technicism and social suffering. Ciência \& Saúde Coletiva, Rio de Janeiro, v. 19, n. 9, p. 3631-3644, 2014.

VALENTIM, M. L. P. (Org.). Informação, conhecimento e inteligência organizacional. 2. ed. Marília: FUNDEPE, 2007.

VENTURA, R. C. M. O.; NASSIF, M. E. Poder e compartilhamento da informação: relações e implicações na arena política organizacional. Em Questão, Porto Alegre, v. 22, n. 2, p. 9-35, 2016.

VON KROGH, G. Facilitando a criação do conhecimento. Rio de Janeiro: Campus, 2002.

WIIG, K. M. Application knowledge management in public administration. Arlington: Knowledge Research Institute, 2000.

ZHANG, D.; ZHOU, L.; NUNAMAKER JR., J. F. A knowledge management framework for the support of decision making in humanitarian assistance/disaster relief. Knowledge and Information Systems, Londres, v. 4, p. 370-385, 2002.

\title{
Knowledge management applied to natural disasters: the case of Civil Defense
}

\begin{abstract}
The civil defense in Brazil is constituted by professionals with competence to work in the management of the risks of natural disasters in the country, since they act directly in the areas of risk and vulnerable population groups in these processes. In this sense, the tacit and explicit knowledge of these professionals is of great importance for the prevention and mainly for operations in the face of disaster and other times of crisis. However, this knowledge is often lost due to the institutional weakness of the civil defense, especially at your local level. Thus, we attempted to make a theoretical relationship on the applicability of the knowledge management concepts in the Civil Defense agencies to generate knowledge for improving service to natural disasters actions.
\end{abstract}

Keywords: Knowledge management. Natural disasters. Civil Defense. 
Recebido em: 30/12/2016

Aceito em: 08/03/2017

${ }^{1}$ BRAUN, A. A. A análise do trabalho voluntariado no Sistema Nacional de Defesa Civil. 2006. 39 f. Trabalho de Conclusão de Curso (Especialização em Planejamento e Gestão em Defesa Civil) - Universidade Federal de Santa Catarina, Florianópolis, 2006. Apud Londe, Soriano e Coutinho (2015).

${ }^{2}$ QUEIROZ, E. M. Consórcio em Defesa Civil: alternativa para o enfrentamento de desastres de origem hídrica nos municípios de pequeno porte, no Brasil. 2010. Dissertação (Mestrado em Defesa e Segurança Civil) - Universidade Federal Fluminense, Niterói, 2010. Apud Queiroz e Bodstein (2011). 